\title{
Социология
}

DOI: 10.17805/ggz.2020.1.7

\section{Образовательные практики в механизмах адаптации к цифровым трансформациям: концептуальные идеи и методологические подходы}

\author{
А. Н. Пинчук
}

Институт соцуиально-политических исследований ФНИСЦ РАН; Российский экономический университет им. Г. В. Плеханова

В статье раскрываются содержание, роль и особенности воспроизводства образовательных практик в механизмах адаптации. Представленная тематика приобретает практическую значимость в контексте формирования циифровой экономики, в которой тесно сопряжены идеи непрерывного образования и активной адаптаџии индивида к динамично меняющимся условиям.

С опорой на обширный теоретический корпус сочиологического знания прорабатываются основы изучения образования на уровне сочииальных практик, реализуемых через различные формы обучения в способах адаптации. В этом ключе разработана схема анализа адаптационного механизма, элементы которого получают содержательную специифику в тех или иньх соцуиальных группах и условиях их сочиальной жизни. В методологическом аспекте показан познавательный потенциал сочиологического инструментария для эмпирического исследования образовательных практик как способа адаптации к изифровым трансформациям в социиально-трудовой сфере.

Ключевые слова: образование; образовательные практики; адаптация; механизмы адаптацчи; стратегии адаптацчин; способы адаптацчии

\section{Educational Practices in Mechanisms of Adaptation to Digital Transfor- mations: Conceptual Ideas and Methodological Approaches}

A. N. Pinchuk

Institute of Socio-Political Research FCTAS RAS;

Plekhanov Russian University of Economics

The article reveals the content, role and features of reproduction of educational practices in adaptation mechanisms. The presented topic acquires practical significance in the context of the formation of the digital economy, in which the ideas of continuous education and active adaptation of the individual to dynamically changing conditions are closely intertwined. 
Using an extensive theoretical body of sociological knowledge, the author discusses the basics of education studies at the level of social practices that are being implemented through various forms of learning in modes of adaptation. In this vein, a scheme for analyzing the adaptation mechanism has been developed, the elements of which gain meaningful specificity in certain social groups and their social life conditions. The methodological aspect shows the cognitive potential of sociological tools for empirical research into educational practices as a way to adapt to digital transformations in the social and labor sphere.

Keywords: education; educational practices; adaptation; adaptation mechanisms; adaptation strategies; ways of adaptation

\section{ВВЕДЕНИЕ}

В условиях повышенной заинтересованности рынка труда в кадрах с развитыми цифровыми компетенциями усиливается внимание к механизмам адаптации современных специалистов к цифровым трансформациям в социально-трудовой сфере. Так, согласно прогнозам аналитиков Всемирного экономического форума, цифровизация различных профессиональных областей станет ведущим трендом реконструирования структуры занятости (Шваб, 2019). По мнению зарубежных авторов, автоматизация рабочих мест может спровоцировать поляризацию рынка труда (Autor, 2015), а также понизить профессиональный статус определенных категорий работников (Sorgner, 2017). Возможные траектории автоматизации рабочих мест осмысливаются и в российских условиях, хотя реальные сдвиги оцениваются достаточно неоднозначно (Капелюшников, 2017). Между тем, отечественные ученые отмечают, что доля потенциально автоматизируемых рабочих мест в России довольно высока и составляет 44,77 \% от общей численности занятых или 20,2 млн работников (Земцов, 2018: Электронный ресурс).

Надо признать, что для России требуют отдельного обсуждения социально-демографические процессы, экономическое состояние, культурные и другие особенности, которые во многом определяют реальные перспективы формирования цифровой экономики. Тем не менее, когда в контексте цифровых трансформаций начинают проявляться новые черты социальной реальности, на передний план выдвигается проблема адаптации специалистов к меняющимся запросам экономики. Собственно, жизнеспособность идеи цифровой экономики во многом зависит от возможности насыщения рынка труда кадрами с востребованными для инновационного развития компетенциями. В докладе, подготовленном в 2019 г. Институтом статистических исследований и экономики знаний НИУ ВШЭ, прежде всего фиксируется рост спроса работодателей на работников с продвинутыми цифровыми навыками, которые владеют IT-инструментами и освоили языки программирования. Среди 
прочих компетенций отмечаются «цифровая ловкость», владение навыками работы с большими данными и инструментами визуализации, системное мышление, развитый эмоциональный интеллект и, что характерно для условий интенсивного обновления информации, способность непрерывно обучаться, а также успешно адаптироваться и функционировать в ситуации неопределенности (Что такое цифровая экономика? ..., 2019: 51). Ссылки на непрерывное образование и адаптацию приобретают особый смысл, если учитывать, что в том же докладе подчеркивается динамичность и гибкость профессиональных ориентиров индивида, который может «менять сферу профессиональной деятельности несколько раз в течение жизни, приобретая новые компетенции и навыки» (там же: 46).

Близкий по характеристикам компетентностный профиль в контексте экономики знаний отражает Целевая модель компетенций 2025, представленная в докладе компании BCG (The Boston Consulting Group) (Россия 2025 ... , 2017: Электронный ресурс). Предложенная в докладе модель включает в себя когнитивные (саморазвитие, организованность, управленческие навыки, достижение результатов, решение нестандартных задач, адаптивность), социально-поведенческие (коммуникация, межличностные навыки, межкультурное взаимодействие) и цифровые навыки (создание систем, обработка и анализ данных) (там же: 20). Вместе с тем адаптация и образование также определяются в приоритетах личностного и профессионального становления: «Чтобы соответствовать стремительным темпам развития экономики знаний и оставаться востребованным на рынке труда, человеку необходимо учиться на протяжении всей жизни и адаптироваться к непрерывным, быстрым и неожиданным изменениям» (там же: 35). Такие ожидания от поведения человека в трансформирующемся обществе требуют прояснения социальных аспектов феномена адаптации и связанных с этим вопросов. Какие социокультурные условия опосредуют потребность в образовании и освоении новых компетенций как наиболее приемлемого способа адаптации? Какое место занимает образование в способах адаптации современных россиян к преобразованиям в социально-трудовой сфере? Насколько реалистична идея о том, что взрослое население россиян будет постоянно обучаться и / или переобучаться, пытаясь адаптироваться к меняющимся условиям (какие способы адаптации могут служить альтернативой)? В данном случае требуется изучение практик участия населения в непрерывном образовании, а вместе с тем и тех образовательных практик, которые будут воспроизводиться в адаптационных механизмах.

Вовлеченность в различные виды образования людей в возрасте от 25 до 65 лет можно проанализировать с опорой на материалы Международной программы оценки компетентности взрослых (Programme for the International 
Assessment of Adult Competences - PIAAC) (Воронина, Попов, 2019). Данные свидетельствуют о том, что общая доля взрослых, получающих формальное и неформальное образование в России (20\%), более чем вдвое меньше аналогичной доли в странах ОЭСР (50\%). Причем наибольший разрыв наблюдается в сфере неформального образования (16\% в России и $46 \%$ в странах ОЭСР). Не менее показательны результаты, фиксирующие высокую долю взрослых высокообразованных россиян $(86,01 \%)$, не желающих получать формальное и неформальное образование (там же: 132-133). Следует также заметить, что в последнее время самообразование является самой распространенной практикой непрерывного образования среди взрослого населения России в возрасте от 25 до 64 лет (24\% согласно данным опроса 2017 г.) (Бондаренко, 2018: 16). Однако россияне существенно отстают от ряда европейских стран, в которых самообразованием охвачена основная часть населения (Дания - $71 \%$, Нидерланды - 73 \%, Италия - 74 \%, Словакия - 75 \%, Швеция - 79 \% и т. д.) (Индикаторы образования, 2018: 50).

Остается открытым вопрос о том, получит ли широкое распространение образование как способ адаптации россиян к цифровым трансформациям? Изучение такой стороны адаптационного процесса представляется перспективным в аспекте практической значимости. Однако возможность анализа затрудняется в связи с недостаточно проработанной теоретико-методологической базой. В рамках исследования социальных образовательных практик как способа адаптации прежде всего следует провести ревизию теоретических подходов и разобрать методологические вопросы. Исходя из этого, выдвигается цель настоящей статьи - проанализировать концептуальные подходы к изучению образовательных практик в способах адаптации к цифровым трансформациям в социально-трудовой сфере и рассмотреть познавательные возможности социологического инструментария для эмпирического исследования данной тематики.

\section{ПОВЕДЕНЧЕСКИЙ АСПЕКТ МЕХАНИЗМА АДАПТАЦИИ: СТРАТЕГИИ И СПОСОБЫ}

В отечественной научно-исследовательской традиции отмечается определенный опыт изучения особенностей образования как фактора адаптации обучающейся молодежи (Абрамова, 2010) либо самообразования как адаптационного ресурса населения в реформирующемся обществе (Ключарев, Кофанова, 2016). Понимание образования как особого фактора или ресурса адаптации репрезентирует различные подходы к объяснению взаимосвязи между социальным феноменом адаптации и сферой образования. Для четкой фокусировки исследовательского анализа, определяемого целью статьи, экс- 
плицируем связующее звено в интерпретации феноменов образования и адаптации.

В социологии адаптации Л.В. Корель выделяет две теоретические школы - системную и интерпретативную, отражающие основные направления развития социологической мысли и, соответственно, очерчивающие рамки артикуляции феномена адаптации (Корель, 2005). Первая теоретическая школа, как ее еще называют структурная или объективистская, исследует общественную жизнь на макроуровне, в то время как интерпретативная или субъективистская научная школа изучает действия индивида на микроуровне, отсылая к идеям «понимающей социологии» М. Вебера, символического интеракционизма, феноменологии, этнометодологии и т. д. (там же: 62). В субъективистском направлении адаптация осмысливается через поведение индивида. Именно социологическое определение адаптивного действия становится значимым эвристическим конструктом для сопряжения с идеями о роли образовательных практик в адаптационных механизмах. Здесь важно отразить теоретико-методологическую перспективу анализа действий адаптанта, а для этого обратиться к особенностям осмысления природы социальной реальности.

Возвращаясь к социологии адаптации, обратим внимание на идеалистический подход к определению социальной реальности как совокупности идей об окружающем мире (там же: 64). С этого угла зрения социальное адаптивное действие является процессом конструирования социальной реальности, наделения ситуации особым смыслом. Через интерпретацию и восприятие условий действительности осуществляется констатация адаптивной ситуации, артикуляция пространства адаптивных действий, выбор адаптивной модели, т. е. генерализирующей стратегии адаптации, выражающейся в приспособлении, не приспособлении или возможности отстраниться от адаптивной угрозы и выжидать нужный момент. В этом плане интерпретация окружающей действительности, восприятие прошлого, настоящего и возможного будущего состояния дел становятся основным элементом адаптивного действия человека (там же: 67).

А. С. Готлиб определяет процесс адаптации как поведенческое и психологическое освоение индивидом актуальных на данный момент условий социального пространства (Готлиб, 2000: 8). Автор считает, что методологически корректно разграничивать и изучать конкретные элементы процесса адаптации (адаптацию в политической сфере, социально-экономическую адаптацию и др.). Между тем не исключается исследование интегральной адаптации для отдельных индивидов. При этом акцент на поведении, а не на ценностных ориентациях, стереотипах, представлениях, позволяет автору рассмотреть деятельность как процесс, который имеет цель, средство и ре- 
зультат и в то же время отражает включенность социального субъекта в меняющееся социальное пространство. В этой теоретической схеме особое внимание привлекают средства, т. е. определенные поведенческие стратегии, через которые достигаются цели (там же: 12).

Принятие цели, определение стратегии и выбор способа адаптации становятся ключевыми характеристиками адаптационного механизма как процесса социализации и реализации преобразующей активности индивида, направленной на изменение своего положения. Цели адаптации, формируемые устремлением к желаемому состоянию, определяют адаптационные стратегии, общие жизненные ориентиры, которые могут отражать как активную, так и пассивную позицию (Козырева, 2004: 19). В рамках той или иной адаптационной стратегии реализуются конкретные способы адаптации «это такое действие или поведение, которое, принимая форму экономического, политического или иного участия, трудовой, общественно-политической, познавательной и иной деятельности, позволяет реализовать, пусть даже частично или ограниченно, адаптационный потенциал или укрепить адаптационные ресурсы» (там же: 20).

Таким образом, конкретные действия позволяют рассмотреть реализацию адаптационных стратегий в практике повседневной жизни. Для анализа способов адаптации представляется целесообразным использовать теорию социальных практик, которая позволяет осмыслить глубокие основы социально сконструированных форм массового поведения, типизацию действий и взаимодействий социальных субъектов, институциональные черты повседневной жизнедеятельности индивидов. Типичные действия, характерные для определенной сферы жизни общества, могут восприниматься как приемлемые способы адаптации, следовательно, практика получения образования вполне вписывается в адаптационные стратегии. Но прежде чем приступить к построению концептуальной модели, артикулирующей в способах адаптации социальные образовательные практики, следует ответить на ряд вопросов о сущностных свойствах адаптации.

Как взаимодействуют индивид и социальная среда в процессе адаптаuุuи? Одной из существенных характеристик адаптации является интерактивность, которая выражается в процессе взаимного приспособления человека и окружающей его социальной среды (Тезаурус социологии ... , 2009: 183). Иными словами, адаптация способствует принятию социальных условий, но при этом и социальная среда может изменяться в зависимости от реализуемых индивидом стратегий адаптаций. Более того, в социологической энциклопедии подчеркивается инновационность адаптационного процесса, что, соответственно, указывает на потенциал к преобразованию социальной реальности (Социологическая энциклопедия ... , 2003а: 17). Истоки данной идеи 
прослеживаются в теории аномии Р. Мертона, последовательно развивающего мысль о том, что рассогласованность институционализированных средств и установленных обществом целей порождает различные типы индивидуального приспособления в зависимости от позиции индивида в социальной структуре, среди которых выделяется инновация (Мертон, 2006: 254).

Адаптацуия - это результат и / или процесс? Аналитически можно провести различие между адаптацией как процессом и адаптированностью как результатом. Как процесс адаптация воспроизводится постоянно, носит перманентный характер, проявляется в различных сферах жизни человека. Адаптационный процесс протекает в рамках социализации, в ходе которой индивид осваивает социальные нормы и ценности, практики, ролевые функции, приспосабливаясь к социокультурным условиям жизни социума (Социологическая энциклопедия ... , 2003b: 446). В то же время адаптация как состояние отражает определенный результат, проявляется через выраженность степени адаптированности. Для изучения адаптированности выделяют объективные и субъективные показатели. Первые характеризуют освоенность в механизмах адаптации принятых в социальной группе паттернов поведения или выработку новых поведенческих стратегий. Посредством субъективных показателей фиксируют состояние социального самочувствия (Козырева, 2004: 23). Адаптация как состояние интегрирована в процесс, она может представлять определенный этап развития данного процесса, который меняет свое направление, свойства, интенсивность в зависимости от состояния, а именно особенностей соответствия социальных ожиданий субъекта и требований и запросов общества (там же).

В какой сфере жизни общества изучают адаптащиюю? Адаптацию анализируют в различных сферах жизнедеятельности индивида и общества (профессиональной, экономической, культурной и т. д.). При этом необходимо помнить о том, что выделенные аналитически пространства социальной жизни пересекаются, плавно перетекают друг в друга в общем плане жизненных стратегий, отражаясь во взаимосвязанных представлениях о социальной реальности.

Что является объектом адаптациии или к чему адаптируются? Адаптация может пониматься как многоуровневая и многоаспектная деятельность. Исходя из этого закономерно рассматривать:

1) приспособление к окружающей среде (микро-, макро-, мезо-);

2) приспособление к определенному образу и стилям жизни - профессии, типу досуга и т. д.;

3) приспособление к конкретным требованиям данного места и данного времени (статуса, роли и т. д.), например, к требованиям вуза, общежития, транспорта и т. д. 
Уже здесь видно, что адаптация у взрослых, детей и молодежи разная и имеет разные цели, они разные и по регионам, по национальным и религиозным приоритетам и т. д. Осмыслить данные особенности адаптации как социального феномена позволяют теоретические положения тезаурусной социологии. В общем виде тезаурус представляет собой свод систематизированных гуманитарных знаний. Заключая в себе представления об окружающем мире, он выступает в качестве ориентационного комплекса, обеспечивая жизнеспособность социального субъекта. Систематизация знаний в тезаурусе осуществляется по принципу «свое - чужое - чуждое», ориентируя человека в социальной реальности как на уровне повседневности частной жизни, так и на уровне масштабных глобальных изменений (Луков, 2018: 37-38). В том, какие способы адаптации воспроизводит социальный субъект, как раз и проявляется его тезаурус, а, следовательно, и его ориентационные стратегии. Здесь проясняется понимание того, почему индивид придерживается определенных целей и способов адаптации, так как в его тезаурусе эти цели и способы определяются как «свои». Аналогичные предположения закономерно сделать в отношении различных социальных групп, представители которых определяют адаптационную ситуацию в триаде «свое - чужое - чуждое» в характерных для данной группы понятиях, представлениях, суждениях. Это опосредует и то, к чему и как стремятся приспособиться одни, к чему и как - другие.

Итак, обобщая теоретические построения о феномене адаптации, будем исходить из того, что адаптация - это деятельность социального субъекта, которая реализуется в разных сферах определенными способами в рамках согласования ожиданий и потребностей индивида с требованиями и условиями социальной реальности. В контексте развития цифровой экономики и цифровых трансформаций на рынке труда адаптация привлекает внимание и как процесс, и как результат. Адаптационный механизм, реализуемый с использованием ресурсов образования, приобретает особую ценность в обществе непрерывного образования. Выделим ключевые элементы аналитической модели адаптационного механизма и покажем роль и значимость образовательных практик как способа адаптации к цифровым трансформациям в социально-трудовой сфере.

Итак, основываясь на интерпретативном подходе, будем исходить из того, что вовлеченность в адаптивную ситуацию опосредует субъективная интерпретация индивидом своего положения в трансформирующихся социокультурных условиях, требующих определенных действий для изменения своей социально-профессиональной позиции. В качестве побуждающей к действию составляющей адаптационного механизма выделим адаптивную потребность, которая актуализируется в контексте адаптивной ситуации. За- 
тем обратим внимание на адаптационные способы, артикулируемые в рамках адаптационной стратегии, выражающей общую направленность действий. Выбор наиболее подходящего по решению индивида способа адаптации необходимо изучать с учетом самооценки своих возможностей и особенностей условий окружающей реальности, а также освоенных в процессе социализации норм, ценностей и наличия релевантного адаптивного опыта. И, наконец, следует попытаться идентифицировать результат (успешность / неуспешность адаптации) на основе поведенческих характеристик и социального самочувствия индивида. В таблице 1 отражены определенные элементы адаптационного механизма, в котором в способах адаптации к цифровым трансформациям в социально-трудовой сфере представлены образовательные практики.

\section{Таблица 1. Образовательные практики в адаптационном механизме Table 1. Educational practices in the adaptation mechanism}

\begin{tabular}{|c|c|}
\hline $\begin{array}{l}\text { бъективная вовлеченность в } \\
\text { оцесс адаптации }\end{array}$ & $\begin{array}{l}\text { Восприятие цифровых трансформаций } \\
\text { на рынке труда, оценка своего положе- } \\
\text { ния в сложившихся условиях }\end{array}$ \\
\hline $\begin{array}{l}\text { Потребность, ориентация на до- } \\
\text { стижение желаемого результата } \\
\text { (изменение своей позиции) }\end{array}$ & $\begin{array}{l}\text { Повысить конкурентоспособность на } \\
\text { рынке труда, освоить востребованные } \\
\text { цифровые компетенции, перейти на вы- } \\
\text { сокооплачиваемую работу, сменить } \\
\text { сферу деятельности и др. }\end{array}$ \\
\hline $\begin{array}{l}\text { Способы адаптации (в рамках } \\
\text { общей стратегии) - выбор } \\
\text { наиболее подходящего по реше- } \\
\text { нию индивида способа адапта- } \\
\text { ции с учетом оценки своих воз- } \\
\text { можностей (роль социальных } \\
\text { условий) и освоенных в процессе } \\
\text { социализации норм, ценностей; } \\
\text { наличие релевантного адаптив- } \\
\text { ного опыта }\end{array}$ & $\begin{array}{l}\text { Образовательные практики (какие виды } \\
\text { социальной практики в сфере образова- } \\
\text { ния выбирают, какие условия опосре- } \\
\text { дуют воспроизводство тех или иных об- } \\
\text { разовательных практик, освоенность } \\
\text { цифровых технологий в данных практи- } \\
\text { ках): } \\
\text { • формальное образование; } \\
\text { • дополнительное образование; } \\
\text { • самообразование. }\end{array}$ \\
\hline Результативность & $\begin{array}{l}\text { Освоенность определенных форм пове- } \\
\text { дения в качестве способов адаптации. } \\
\text { Состояние социального самочувствия. }\end{array}$ \\
\hline
\end{tabular}


Методологически важно положение Л. В. Корель о том, что изучение адаптационного механизма направлено на выявление приспособительного поведения безотносительно к успешности / неуспешности адаптации. Такая «позиция ставит во главу угла представление (посылку) о достаточности наличия самого факта адаптивной потребности, адаптивной цели, адаптивного поведения вне зависимости от конечного результата - “адаптивного исхода”» (Корель, 2005: 259). Именно на этой стороне адаптационного механизма сконцентрируем основное внимание, репрезентируя образовательные практики в способах адаптации, определяемых потребностью в образовании.

\section{ОБРАЗОВАНИЕ КАК СОЦИАЛЬНАЯ ПРАКТИКА И СПОСОБ АДАПТАЦИИ}

Как социальная практика образование рассматривается с опорой на обширный корпус теорий, репрезентирующих повседневность в основе социальной жизни (М. Мосс, К. Гирц, А. Шюц, П. Бергер, Т. Лукман, П. Бурдье, Э. Гидденс, Г. Гарфинкель, Дж. Серл и др.). Надо заметить, что обновление проблематики повседневности в конструктивистских подходах привело к расцвету научной мысли об основах социальной жизни в контексте преодоления классических оппозиций социально-гуманитарного знания: коллективного и индивидуального, объективного и субъективного (Коркюф, 2002). В этих теоретических подходах можно выделить значимые для осмысления сущности образовательных практик идеи. Во-первых, образовательные практики носят характер опривыченных действий, которые в результате хабитуализации воспроизводят социальные институты (Бергер, Лукман, 1995). Вовторых, образовательные практики опосредованы габитусом, который как «приобретенная система порождающих схем делает возможным свободное продуцирование любых мыслей, восприятий и действий, вписанных в границы, свойственные особенным условиям производства данного габитуса, и только им» (Бурдье, 2017: 106). Этим объясняется необходимость исследования социальных условий формирования и воспроизводства образовательных практик, которые не могут выйти за рамки данных условий, но при этом могут проявить вариативность действий. В-третьих, следует учитывать, что образовательные практики являются «рутиной», для них характерна «повторяемость... в одинаковой манере день за днем» (Гидденс, 2005: 18). Можно сказать, что в таком теоретическом ракурсе происходит переключение внимания на повседневный контекст образования, который позволяет выявить конкретные опривыченные, опосредованные условиями своего конституирования и воспроизводства соответствующие действия (Пинчук, 2016).

В западной литературе социальные образовательные практики в повседневной жизни осмысливаются в процессе непрерывного образования (Jarvis, 
2007). Важно подчеркнуть, что концепция непрерывного образования базируется на идее постоянного обновления знаний, а не дискретного, прерывающегося учебного процесса (Меморандум ..., 2006: Электронный ресурс). Эмпирическое исследование образования длиною в жизнь по существу требует отдельного изучения образовательных траекторий в аспекте динамики, а вместе с тем обсуждения возникающих методологических вопросов (Блоссфельд, Букхольц, 2016). Поэтому артикулируя тему вовлеченности в непрерывное образование в тесной связи с социальными образовательными практиками, мы можем говорить о практиках участия индивида в различных видах образования в ситуации «здесь и сейчас» и обратить внимание на социальные условия конструирования данных практик.

Следует отметить, что тема образовательных практик чаще всего раскрывается и прорабатывается в контексте формального образования (Пинчук, 2017). В последнее время возрастает интерес к практикам дополнительного образования студенческой молодежи и взрослых, что обусловлено необходимостью исследования различных практик участия в непрерывном образовании (Меренков, Сущенко, 2016). В информальном образовании, роль которого в непрерывном обучении становится все очевидней, диапазон образовательных практик достаточно обширен и разнообразен, поэтому охватить и изучить их на эмпирическом уровне достаточно проблематично. Это обусловлено характером информального образования, которое пронизывает повседневную жизнь индивида и осуществляется неосознанно, ненамеренно, стихийно в процессе ежедневных взаимодействий, по существу являясь обучением на основе опыта (Formal, non-formal and informal learning, б/д: Электронный ресурс).

В рамках информального образования представляется обоснованным артикулировать практики самообразования, которые имеют определенную направленность, содержание, специфику реализации в контексте самоорганизованного социальным субъектом учебного процесса с учетом доступных для самообразования ресурсов и возможностей, а также социокультурных особенностей и условий его повседневной жизни. В этом случае практики самообразования репрезентируют автономно выработанные способы использования человеком открытого и доступного в обыденной жизни информационного пространства для самообучения.

В способах адаптации образовательные практики играют существенную роль, способствуя достижению адаптивных целей через освоение новых компетенций посредством различных форм обучения. Здесь следует задуматься над тем, что, собственно, образовательные практики постоянно меняются, расширяются границы образовательной среды, организованной с использованием цифровых технологий, все больше распространяются практики 
использования сети Интернет. Знают ли о новых возможностях в образовании взрослые, которые учились в школах или получали профессиональное образование в традиционной форме несколько десятилетий назад? Используют ли доступные образовательные ресурсы в Интернете для самообразования? Правомерно будет замечание о том, что здесь затрагивается приспособление к самой системе образования, что, безусловно, заслуживает специального анализа. В нашем случае внимание приковано к освоенности образования в адаптационных механизмах населения, а вместе с тем и к тем условиям, которые опосредуют воспроизводство данных способов адаптации в социально-экономической жизни общества. Какие это условия? Какое место образование занимает в различных адаптационных стратегиях россиян? Среди каких социальных групп населения преобладают практики дополнительного образования и какие конкретно виды ДПО воспроизводятся? Кто чаще всего занимается самообразованием и какие практики самообразования доминируют среди представителей тех или иных профессиональных групп, либо в различных возрастных группах и т. д.?

Эти вопросы очерчивают обширное исследовательское поле, открытое для эмпирических исследований. Стоит отметить, что социологическая наука обладает достаточно мощным инструментарием, позволяя изучать различные стороны феномена адаптации, в том числе, способы адаптации и входящие в них социальные практики. Разработка инструментария становится непростой интеллектуальной задачей, так как исследовать адаптацию достаточно сложно, тем более что многие аспекты адаптации как процесса протекают неосознанно в жизни человека, однако становятся ключевыми механизмами приспособления к социальной действительности. В рамках интерпретативизма (Браймен, Белл, 2012) утверждается, что посредством качественных методов можно получить достаточно насыщенный, познавательный материал о субъективном восприятии социальной реальности, повседневных представлениях и миропонимании индивида, об ориентационных стратегиях человека в окружающем мире. Так, в ходе интервьюирования можно выявить представления респондента о ситуации, сложившейся на современном рынке труда, артикулировать внутренние мотивы, побуждающие к выбору того или иного способа адаптации, проанализировать самооценку профессиональных компетенций и своего положения в сфере занятости, зафиксировать высказанные своими словами мысли о происходящих цифровых трансформациях. Эта важная информация, которая позволит осмыслить механизмы адаптации в особом аспекте и понять, что опосредует воспроизводство практик образования в способах адаптации к новым условиям социальной реальности, а что способно помешать этому. Полученные таким образом данные приобретают как теоретическую, так и практическую значимость. 


\section{ЗАКЛЮЧЕНИЕ}

Сегодня тема адаптации к условиям формирующейся цифровой реальности приобретает особое звучание в научно-практическом плане. Так, отмеченные в общих чертах приоритеты развития цифровой экономики свидетельствуют о важности непрерывного обучения современных специалистов и их адаптации к меняющемуся миру, однако механизм реализации такой идеи требует отдельного обсуждения. Проясняет суть дела интерпретация образования в механизмах адаптации, которые в едином ключе приобретают особые свойства. На данный момент обозначены концептуально-методологические аспекты анализа образовательных практик как способа адаптации, но перспективность темы оставляет простор для дальнейших исследований. Здесь следует отметить и то, что развитие представленной тематики может менять свое направление, придавая первостепенную значимость тем или иным сторонам социальной реальности, тем более, когда многие изменения - то, с чем еще предстоит столкнуться, осмысливаются как возможные траектории. Однако стоит признать и то, что актуальность образования в способах адаптации не ограничивается сегодняшним днем, оставляя открытыми границы для дальнейшего изучения.

\section{СПИСОК ЛИТЕРАТУРЫ}

Абрамова, М. А. (2010) Образование как фактор социокультурной адаптации учащейся молодежи к условиям современных трансформаций // Вопросы образования. № 3. С. 195-212.

Бергер, П., Лукман, Т. (1995) Социальное конструирование реальности: трактат по социологии знания / пер. с англ. Е. Руткевич. М. : Academia-Центр ; Медиум. 323 с.

Блоссфельд, Х.-П., Букхольц, С. (2016) Образование как непрерывный процесс. Введение в сравнительные исследования образовательных траекторий в современных обществах в рамках проекта eduLIFE // Журнал социологии и социальной антропологии. Т. 19. № 5 (88). С. 5-14.

Бондаренко, Н. В. (2018) Непрерывное образование взрослого населения в России: вовлеченность, источники финансирования и основные эффекты от участия : информационный бюллетень. М. : НИУ ВШЭ. 32 с. (Мониторинг экономики образования № 12 (132)).

Браймен, А., Белл, Э. (2012) Методы социальных исследований. Группы, организации и бизнес. Харьков : Гуманитарный центр. 776 с.

Бурдье, П. (2017) Практический смысл. СПб. : Алетейя. 560 с.

Воронина, Н. Д., Попов, Д. С. (2019) Востребованность образования взрослых и факторы, связанные с участием в нем: Россия на фоне стран ОЭСР // Экономическая социология. Т. 20. № 2. С. 122-153. 
Гидденс, Э. (2005) Устроение общества: очерк теории структурации. 2е изд. М. : Академический проект. 528 с.

Готлиб, А. С. (2000) Социально-экономическая адаптация россиян: опыт сочетания количественной и качественной методологии в одном отдельно взятом исследовании // Социология: методология, методы, математическое моделирование (4M). № 12. С. 5-24.

Земцов, С. П. (2018) Потенциальная роботизация и экономика незнания в регионах России : доклад к XIX Апрельской Международной научной конференции по проблемам развития экономики и общества, Москва, 10-13 апр. 2018 г. [Электронный ресурс] // Институт экономической политики имени Е. Т. Гайдара (Институт Гайдара). URL: https://www.iep.ru/files/news/zemtsov 10.04.18.pdf [архивировано в WaybackMachine] (дата обращения: 10.01.2020). DOI: $10.13140 / R G .2 .2 .11496 .98567$

Индикаторы образования (2018) : статистический сборник / Н. В. Бондаренко, Л. М. Гохберг, Н. В. Ковалева и др. ; Нац. исслед. ун-т «Высшая школа экономики». М. : НИУ ВШЭ. 400 с.

Капелюшников, Р. И. (2017) Технологический прогресс - пожиратель рабочих мест? // Вопросы экономики. № 11. С. 111-140. DOI: 10.32609/00428736-2017-11-111-140

Ключарев, Г. А., Кофанова, Е. Н. (2016) Самообразование как адаптационный ресурс // Россия реформирующаяся : ежегодник : сб. науч. ст. / отв. ред. М. К. Горшков ; Институт социологии РАН. М. : Новый хронограф. Вып. 14. 496 с. С. $282-308$.

Козырева, П. М. (2004) Процессы адаптации и эволюция социального самочувствия россиян на рубеже XX-XXI веков. М. : Центр общечеловеческих ценностей. 320 с.

Корель, Л. В. (2005) Социология адаптаций: вопросы теории, методологии и методики. Новосибирск : Наука. 424 с.

Коркюф, Ф. (2002) Новые социологии. СПб. : Алетейя. 172 с.

Луков, В. А. (2018) Тезаурусная социология : в 4 т. М. : Изд-во Моск. гуманит. ун-та. Т. 1.608 с.

Меморандум непрерывного образования Европейского Союза (A memorandum on lifelong learning) (2006) / Commission of the European Communities. Brussels, 30.10.2000 SEC (2000) 1832 [Электронный ресурс] // Адукатар. № 2 (8). C. 24-27. URL: http://adukatar.net/wp-content/uploads/2009/12/Adu_8_Pages 24-27.pdf [архивировано в WaybackMachine] (дата обращения: 10.01. 2020).

Меренков, А. В., Сущенко, А. Д. (2016) Потребности студентов вузов в дополнительном образовании: особенности формирования и реализации // 
Вопросы образования. № 3. C. 204-223. DOI: 10.17323/1814-9545-2016-3-204$\underline{223}$

Мертон, Р. (2006) Социальная теория и социальная структура. М. : АСТ ; АСТ Москва ; Хранитель. 873 с.

Пинчук, А. Н. (2016) Образовательные практики в концептуальном поле социологии // Знание. Понимание. Умение. № 4. С. 321-331. DOI: 10.17 805/zpu.2016.4.29

Пинчук, А. Н. (2017) Проблема образовательных практик обучающихся вузов как потребителей образовательных услуг // Вестник Адыгейского государственного университета. Серия 1: Регионоведение: философия, история, социология, юриспруденция, политология, культурология. № 3 (204). С. 143151.

Россия 2025: от кадров к талантам (2017) / подг. В. Бутенко, К. Полунин, И. Котов, Е. Сычева, А. Степаненко, Е. Занина, С. Ломп, В. Руденко, Е. Топольская [Электронный ресурс] // The Boston Consulting Group. 30 октября. URL: https://www.bcg.com/ru-ru/perspectives/188095 [архивировано в WaybackMachine] (дата обращения: 10.01.2020).

Социологическая энциклопедия (2003а) : в 2 т. / Нац. общ.-науч. фонд ; рук. науч. проекта Г. Ю. Семигин ; гл. ред. В. Н. Иванов. М. : Мысль. Т. 1. $694 \mathrm{c}$.

Социологическая энциклопедия (2003b) : в 2 т. / Нац. общ.-науч. фонд ; рук. науч. проекта Г. Ю. Семигин ; гл. ред. В. Н. Иванов. М. : Мысль. Т. 2. $863 \mathrm{c}$.

Тезаурус социологии (2009) : темат. слов.-справ. / под ред. Ж. Т. Тощенко. М. : ЮНИТИ-ДАНА. 487 с.

Что такое цифровая экономика? Тренды, компетенции, измерение (2019) : доклад к XX Апрельской Международной научной конференции по проблемам развития экономики и общества, Москва, 9-12 апр. 2019 г. / Г. И. Абдрахманова, К. О. Вишневский, Л. М. Гохберг и др. ; науч. ред. Л. М. Гохберг ; Нац. исслед. ун-т «Высшая школа экономики». М. : Изд. дом Высшей школы экономики. 82, [2] с. Режим доступа: https://conf.hse.ru/mirror/ pubs/share/262126147 [архивировано в WaybackMachine] (дата обращения: 10.01.2020).

Шваб, К. (2019) Четвертая промышленная революция. М. : Эксмо. 288 c.

Autor, D. H. (2015) Why are there still so many jobs? The history and future of workplace automation // Journal of Economic Perspectives. Vol. 29. No. 3. P. 3-30. DOI: $10.1257 /$ jep.29.3.3

Formal, non-formal and informal learning (б/д) [Электронный ресурс] // Council of Europe. URL: https://www.coe.int/en/web/lang-migrants/formal-non- 
formal-and-informal-learning [архивировано в WaybackMachine] (дата обращения: 10.01.2020).

Jarvis, P. (2007) The lifelong learning and the learning society : [in 3 vols.] L. ; N. Y. : Routledge. Vol. 2: Globalisation, lifelong learning and the learning society: Sociological perspectives. xii, $238 \mathrm{p}$.

Sorgner, A. (2017) The automation of jobs: A threat for employment or a source of new entrepreneurial opportunities? // Foresight and STI Governance. Vol. 11. No. 3. P. 37-48. DOI: $\underline{10.17323 / 2500-2597.2017 .3 .37 .48}$

Дата поступления: 17.01.2020 г.

\section{REFERENCES}

Abramova, M. A. (2010) Obrazovanie kak faktor sotsiokul'turnoi adaptatsii uchashcheisia molodezhi k usloviiam sovremennykh transformatsii [Education as a factor of socio-cultural adaptation of student youth to the conditions of modern transformations]. Voprosy obrazovaniia, no. 3, pp. 195-212. (In Russ.).

Berger, P. and Luckmann, T. (1995) Sotsial'noe konstruirovanie real'nosti: traktat po sotsiologii znaniia [The social construction of reality: A treatise in the sociology of knowledge] / transl. from English by E. Rutkevich. Moscow : Academia-Tsentr Publ. ; Medium Publ. 323 p. (In Russ.).

Blossfeld, H.-P. and Buchholz, S. (2016) Obrazovanie kak nepreryvnyi protsess. Vvedenie $\mathrm{v}$ sravnitel'nye issledovaniia obrazovatel'nykh traektorii v sovremennykh obshchestvakh $\mathrm{v}$ ramkakh proekta eduLIFE [Education as a lifelong process. An introduction to the comparisons of educational trajectories in modern societies from the eduLIFE project]. Zhurnal sotsiologii i sotsial'noi antropologii, vol. 19, no. 5 (88), pp. 5-14. (In Russ.).

Bondarenko, N. V. (2018) Nepreryvnoe obrazovanie vzroslogo naseleniia $v$ Rossii: vovlechennost', istochniki finansirovaniia i osnovnye effekty ot uchastiia [Lifelong learning for adults in Russia: Involvement, sources of funding and the main effects of participation] : An information bulletin. Moscow : HSE Publ. House. 32 p. (Monitoring ekonomiki obrazovaniia / Monitoring of education economics, no. 12 (132)). (In Russ.).

Bryman, A. and Bell, E. (2012) Metody sotsial'nykh issledovanii. Gruppy, organizatsii i biznes [Business research methods]. Kharkov : Gumanitarnyi tsentr / Humanitarian Centre Publ. 776 p. (In Russ.).

Bourdieu, P. (2017) Prakticheskii smysl [Le Sens pratique / Practical reason]. St. Petersburg : Aleteiia Publ. 560 p. (In Russ.).

Voronina, N. D. and Popov, D. S. (2019) Vostrebovannost' obrazovaniia vzroslykh i faktory, sviazannye s uchastiem v nem: Rossiia na fone stran OESR 
[Participation in adult education: Russia in comparison with OECD countries]. Ekonomicheskaia sotsiologiia, vol. 20, no. 2, pp. 122-153. (In Russ.).

Giddens, E. (2005) Ustroenie obshchestva: ocherk teorii strukturatsii [The constitution of society: Outline of the theory of structuration]. 2nd edn. Moscow : Akademicheskii proekt Publ. 528 p. (In Russ.).

Gotlib, A. S. (2000) Sotsial'no-ekonomicheskaia adaptatsiia rossiian: opyt sochetaniia kolichestvennoi i kachestvennoi metodologii v odnom otdel'no vziatom issledovanii [Socio-economic adaptation of Russians: Experience of combining quantitative and qualitative methodology in a single study]. Sotsiologiia: metodologiia, metody, matematicheskoe modelirovanie (4M), no. 12, pp. 5-24. (In Russ.).

Zemtsov, S. P. (2018) Potentsial'naia robotizatsiia i ekonomika neznaniia v regionakh Rossii [Potential robotics and the economics of ignorance] : A report on the 19th April International Academic Conference on Economic and Social Development, Moscow, April 10th-13th, 2018. Institut ekonomicheskoi politiki imeni E. T. Gaidara (Institut Gaidara) [Gaidar Institute for Economic Policy (The Gaidar Institute)] [online] Available at: https://www.iep.ru/files/news/zemtsov_10.04.18. pdf [archived in WaybackMachine] (accessed 10.01.2020). (In Russ.). DOI: 10.13140/RG.2.2.11496.98567

Indikatory obrazovaniia [Education indicators] (2018) : A statistical collection / N. V. Bondarenko, L. M. Gokhberg, N. V. Kovaleva et al. ; National Research University "Higher School of Economics". Moscow : HSE Publ. House. 400 p. (In Russ.).

Kapeliushnikov, R. I. (2017) Tekhnologicheskii progress — pozhiratel' rabochikh mest? [Is technological change a devourer of jobs?]. Voprosy ekonomiki, no. 11, pp. 111-140. (In Russ.). DOI: 10.32609/0042-8736-2017-11-111-140

Kliucharev, G. A. and Kofanova, E. N. (2016) Samoobrazovanie kak adaptatsionnyi resurs [Self-education as adaptation resources]. In: Rossiia reformiruiushchaiasia [Reforming Russia] : A yearbook : A collection of articles / ed. by M. K. Gorshkov ; Institute of Sociology RAS. Moscow : Novyi khronograf Publ. Issue 14. 496 p. Pp. 282-308. (In Russ.).

Kozyreva, P. M. (2004) Protsessy adaptatsii i evoliutsiia sotsial'nogo samochuvstviia rossiian na rubezhe $X X-X X I$ vekov [Adaptation processes and evolution of social feeling of the Russians at the turn of the 20th-21st centuries]. Moscow : Tsentr obshchechelovecheskikh tsennostei / Center for Universal Values Publ. 320 p. (In Russ.).

Korel, L. V. (2005) Sotsiologiia adaptatsii: voprosy teorii, metodologii $i$ metodiki [Sociology of adaptations: Questions of theory, methodology and techniques]. Novosibirsk : Nauka Publ. 424 p. (In Russ.). 
Corcuff, P. (2002) Novye sotsiologii [Les nouvelles sociologies / New sociologies]. St. Petersburg. : Aleteiia Publ. 172 p. (In Russ.).

Lukov, V. A. (2018) Tezaurusnaia sotsiologiia [Thesaurus sociology] : in 4 vols. Moscow : Moscow University for the Humanities Publ. Vol. 1. 608 p. (In Russ.).

Memorandum nepreryvnogo obrazovaniia Evropeiskogo Soiuza [A memorandum on lifelong learning of the European Union] (2006) / Commission of the European Communities. Brussels, 30.10.2000 SEC (2000) 1832. Adukatar, no. 2 (8), pp. 24-27. [online] Available at: http://adukatar.net/wp-content/uploads/2009/ 12/Adu 8 Pages 24-27.pdf [archived in WaybackMachine] (accessed 10.01. 2020). (In Russ.).

Merenkov, A. V. and Sushchenko, A. D. (2016) Potrebnosti studentov vuzov v dopolnitel'nom obrazovanii: osobennosti formirovaniia i realizatsii [How students develop and meet their need for additional education]. Voprosy obrazovaniia, no. 3, pp. 204-223. (In Russ.). DOI: 10.17323/1814-9545-2016-3-204$\underline{223}$

Merton, R. (2006) Sotsial'naia teoriia i sotsial'naia struktura [Social theory and social structure]. Moscow : AST Publ. ; AST Moskva Publ. ; Khranitel' Publ. 873 p. (In Russ.).

Pinchuk, A. N. (2016) Obrazovatel'nye praktiki v kontseptual'nom pole sotsiologii [Educational practice as a sociological concept]. Znanie. Ponimanie. Umenie, no. 4, pp. 321-331. (In Russ.). DOI: 10.17805/zpu.2016.4.29

Pinchuk, A. N. (2017) Problema obrazovatel'nykh praktik obuchaiushchikhsia vuzov kak potrebitelei obrazovatel'nykh uslug [The problem of educational practices of university students as consumers of educational services]. Vestnik Adygeiskogo gosudarstvennogo universiteta. Seriia 1: Regionovedenie: filosofiia, istoriia, sotsiologiia, iurisprudentsiia, politologiia, kul'turologiia, no. 3 (204), pp. 143-151. (In Russ.).

Rossiia 2025: ot kadrov k talantam [Russia 2025: Resetting the talent balance] (2017) / prepared by V. Boutenko, K. Polunin, I. Kotov, E. Sycheva, A. Stepanenko, E. Zanina, S. Lomp, V. Rudenko, E. Topolskaya. The Boston Consulting Group, October 30. [online] Available at: https://www.bcg.com/ru-ru/perspectives/188095 [archived in WaybackMachine] (accessed 10.01.2020). (In Russ.).

Sotsiologicheskaia entsiklopediia [Sociological encyclopedia] (2003a) : in 2 vols. / National Public and Scientific Foundation ; research manager G. Yu. Semigin ; ed. by V. N. Ivanov. Moscow : Mysl' Publ. Vol. 1. 694 p. (In Russ.).

Sotsiologicheskaia entsiklopediia [Sociological encyclopedia] (2003b) : in 2 vols. / National Public and Scientific Foundation ; research manager G. Yu. Semigin ; ed. by V. N. Ivanov. Moscow : Mysl' Publ. Vol. 2. 863 p (In Russ.). 
Tezaurus sotsiologii [The thesaurus of sociology] (2009) : A subject-based dictionary and reference book / ed. by Zh. T. Toshchenko. Moscow : UNITYDANA Publ. 487 p. (In Russ.).

Chto takoe tsifrovaia ekonomika? Trendy, kompetentsii, izmerenie [What is the digital economy? Trends, competencies, measurement] (2019) : A report on the 20th April International Academic Conference on Economic and Social Development, Moscow, April 9th-12th, 2019 / G. I. Abdrakhmanova, K. O. Vishnevskii, L. M. Gokhberg et al. ; ed. by L. M. Gokhberg ; National Research University "Higher School of Economics". Moscow : HSE Publ. House. 82, [2] p. [online] Available at: https://conf.hse.ru/mirror/pubs/share/262126147 [archived in WaybackMachine] (accessed 10.01.2020). (In Russ.).

Schwab, K. (2019) Chetvertaia promyshlennaia revoliutsiia [The fourth industrial revolution]. Moscow : Eksmo Publ. 288 p. (In Russ.).

Autor, D. H. (2015) Why are there still so many jobs? The history and future of workplace automation. Journal of Economic Perspectives, vol. 29, no. 3, pp. 330. DOI: $10.1257 /$ jep.29.3.3

Formal, non-formal and informal learning (s/d) Council of Europe [online] Available at: https://www.coe.int/en/web/lang-migrants/formal-non-formal-and-informal-learning [archived in WaybackMachine] (accessed 10.01.2020).

Jarvis, P. (2007) The lifelong learning and the learning society : [in 3 vols.] London ; New York : Routledge. Vol. 2: Globalisation, lifelong learning and the learning society: Sociological perspectives. xii, $238 \mathrm{p}$.

Sorgner, A. (2017) The automation of jobs: A threat for employment or a source of new entrepreneurial opportunities? Foresight and STI Governance, vol. 11, no. 3, pp. 37-48. DOI: 10.17323/2500-2597.2017.3.37.48

Submission date: 17.01.2020.

Пинчук Антонина Николаевна - кандидат социологических наук, научный сотрудник Института социально-политических исследований РАН; ассистент кафедры политологии и социологии Российского экономического университета им. Г. В. Плеханова. Адрес: 117997, Россия, г. Москва, Стремянный пер., д. 128. Тел.: +7 (495) 958-23-27. Эл. адрес: antonina.pinchuk27@ $\underline{\text { bk.ru }}$

Pinchuk Antonina Nikolaevna, Candidate of Sociology, Research Associate, Institute of Socio-Political Research FCTAS RAS; Assistant Lecturer, Department of Political Science and Sociology, Plekhanov Russian University of Economics. Postal address: 128 Stremyannyi Lane, 117997 Moscow, Russian Federation. Tel.: +7 (495) 958-23-27. E-mail: antonina.pinchuk27@bk.ru 
Для ичитирования:

Пинчук A. Н. Образовательные практики в механизмах адаптации к цифровым трансформациям: концептуальные идеи и методологические подходы [Электронный ресурс] // Горизонты гуманитарного знания. 2020. № 1. C. 95-114. URL: http://journals.mosgu.ru/ggz/article/view/1165 (дата обращения: дд.мм.гггг). DOI: 10.17805/ggz.2020.1.7 